\title{
Trends in Inequality in Maternal and Child Health and Health Care in Uganda: Analysis of the Uganda Demographic and Health Surveys
}

Alex Ayebazibwe Kakama ( $\square$ alexkakama@gmail.com )

Bishop Stuart University

\section{Research Article}

Keywords: Health inequalities, Health Inequity, Health Disparities, Maternal and child health

Posted Date: August 10th, 2021

DOI: https://doi.org/10.21203/rs.3.rs-764758/v1

License: () (1) This work is licensed under a Creative Commons Attribution 4.0 International License. Read Full License 


\section{Abstract}

Background: Uganda has made great strides in improving maternal and child health. However, little is known about how this improvement has been distributed across different socioeconomic categories, and how the health inequalities have changed over time. This analyses data from three Demographic and Health Surveys (DHS) conducted in 2006, 2011, and 2016 in Uganda to assess trends in inequality for a variety of mother and child health and health care indicators.

Methods: The indicators studied are widely acknowledged as critical for monitoring and evaluating maternal and child health status. These include infant and child mortality, underweight status, stunting, and prevalence of diarrhea.

Antenatal care, skilled birth attendance, delivery in health facilities, contraception prevalence, full immunization coverage, and medical treatment for child diarrhea and URI symptoms are all health care indicators. Two metrics of inequity were used: the quintile ratio, which evaluates discrepancies between the wealthiest and poorest quintiles, and the concentration index, which utilizes data from all five quintiles.

Results: The study found extraordinary, universal improvement in population averages in most of the indices, ranging from the poorest to the wealthiest groups, as well as between rural and urban areas. However, significant socioeconomic and rural-urban disparities persist. Under-five mortality, malnutrition in children (Stunting and Underweight), the prevalence of anaemia, mothers with low BMI, and the prevalence of ARI were found to have worsening inequities.

Healthcare utilization measures such as skilled birth attendants, facility delivery, contraceptive prevalence rate, child immunization, and ITN usage were found to be significantly improving or lowering disparity levels towards a perfect equity stance.

Three healthcare utilization indicators, namely medical treatment for diarrhea, medical treatment for ARI symptoms, and medical treatment for fever, demonstrated a completely perfect equitable situation.

Conclusion: Increased use of health services among the poor and rural populations leads to improved health status and, as a result, the elimination of disparities between the poor and the wealthy, rural and urban people.

Recommendation: Intervention initiatives should prioritize the impoverished and rural communities while also considering the wealthier and urban groups.

\section{Introduction}

Equity is one of the basic principles of the Primary Health Care, and it is reflected in most countries' health policy [1]. Despite governments' commitment to promoting pro-poor health policies and interventions, levels of disparity in health status and utilization of basic health care interventions remain high throughout Sub-Saharan Africa [2]. Evidence suggests that in Sub-Saharan African countries, healthcare consumption is determined not by need, but by wealth, geographical location, education, and individuals' ability to pay [3]. Access to healthcare tends to follow the 'inverse care law', which supposes that the wealthy, who have a lower need for healthcare, have better access to quality care, while the poor and marginalized, who have a greater need, have limited access to quality care [4]. In South Africa, the impoverished have worse health than the wealthy [5]. Similarly, in Uganda, the poor are sicker and have less access to publicly funded health services than their wealthier counterparts [6]; and household welfare status has been highlighted as a critical predictor of health inequalities in Uganda [7].

\section{Conceptualizing Equity and therefore Inequities}

Inequalities, disparities, and inequities are commonly used interchangeably [8-9], although all refer to discrepancies in the utilization or access to services by various groups. Health disparities are differences in the use or access to healthcare services that are unnecessary, preventable, unfair, and unjust [10]. Equity in healthcare refers to ensuring that all individuals have access to a minimum standard of treatment based on need rather than any other factor, such as financial position, geographical location, or capacity to pay [10].

\section{Profile of the Country}

Uganda is a landlocked country in East Africa with a total land area of 241,559 square kilometers and a population of 44.3 million people [11]. Uganda is classed as a low-income country by the World Bank, with a low human development index (HDI of 0.544), ranking 159th out of 189 countries [12]. Up to 21.4 percent of the population lives in poverty, with less than US\$ 1 per person per day [12]. Overall health expenditure per capita is $\$ 43$, and total health expenditure accounts for 6.5 percent of GDP [13]. Uganda's health and development indices are shown in Table 1 below.

Table 1

Table showing selected development and health indicators of Uganda 


\begin{tabular}{|ll|}
\hline Indicator & Value \\
\hline Adult literacy rate (2018) & $76.5 \%$ \\
\hline Life expectancy at birth (male/female) (years) (2018) & 63.4 \\
\hline Infant mortality rate (per 1000 live births) (2018) & 33.4 \\
\hline Under-five mortality rate (per 1000 live births) (2018) & 45.8 \\
\hline Total fertility rate (2018) & 4.9 \\
\hline Maternal mortality ratio (per 100,000 live births) (2018) & 375 \\
\hline Percent of children ages 12-23 months with measles immunization & 86 \\
\hline Adult (15-49 years) HIV prevalence rate (\%) (2018) & 5.8 \\
\hline Source: World Bank (2021). & \\
\hline
\end{tabular}

\section{Statement of the Problem}

In the previous few decades, Uganda has made significant progress in improving maternal and child health. However, little is known about how this development has been distributed among different socioeconomic groups, and how health inequalities have altered over time. In Uganda, research on health disparities is scarce. The majority of studies on health inequalities have concentrated on a single health indicator, and none have examined trends in inequality. For instance, [14] investigated urban-rural discrepancies in COPD management and access in Uganda. Also, [7] used data from Uganda demographic and health surveys to study the factors of child nutrition status in Uganda. Using data from three successive Demographic and Health Surveys (DHS) from 2006, 2011, and 2016, this study assesses the degree and trends in disparities for a variety of indicators of maternal and child health and health care for varied socioeconomic categories, rural and urban populations.

\section{Methodology}

\section{The aim:}

The goal of this study was to analyze equity trends in Uganda for several indices of maternal and child health and healthcare, utilizing data from the Uganda Demographic and Health Surveys of 2006, 2011, and 2016. Specifically, the study assessed the differences in absolute percentage changes in population averages between the wealthiest and poorest, rural and urban populations; calculated the quintile ratios and concentration indices to determine the magnitude and trend of inequalities, and identified markers indicating whether equity levels are improving or worsening.

\section{Justification and Significance}

Monitoring the levels and trends in health inequalities and health service utilization is critical for intervention programs that allocate finite public resources to people who are disadvantaged and have greater needs. The findings of this study may be used by other researchers in the design of future investigations. The findings can help policymakers and technocrats establish relevant health policies and initiatives that promote health equity. Ugandan communities might gain because subsequent policies and actions shall become more responsive to local needs.

\section{Theoretical framework}

The social ecological model [15] was used in this study to give a framework for understanding the complex interplay of personal and contextual factors that affect equity in health and healthcare.

According to the Social-Ecological Model, health is influenced by a variety of subsystems that occur at many levels rather than merely by biological variables. Individual, interpersonal, institutional, community, and public policy are examples of these levels. Understanding that multi-level social variables not only cause but also perpetuate injustices, is critical to understanding health disparities in the past and present [15].

Variables such as socioeconomic status, gender, religion, race, ethnicity, and age, as well as attitudes, actions, and knowledge that affect health are considered at the individual level. The interpersonal level is made up of formal and informal interactions that can build social identities or play different functions in an individual's life, such as; help with social or emotional issues. Institutions at the institutional level shape behaviors and attitudes through organizational characteristics, regulations, norms (formal and informal), and cultural expectations. The community level refers to an individual's living environment, which may enforce specific social standards, offer access to resources, and establish social networks. The Public Policy level encompasses laws and policies (at the local, regional, and national levels) that may have an impact on health outcomes [16]. 


\section{Source of data}

This study makes use of data from three Uganda Demographic and Health Surveys (UDHS), which were conducted in 2006, 2011, and 2016. Up to $9,864,10,086$, and 20,791 households participated in the three polls of 2006,2011 , and 2016 respectively.

The surveys included interviews with all women between the ages of 15 and 49 and men between the ages of 15 and 54 living in the sampled households. In 2006, there were 8,531 women and 2,503 men interviewed; in 2011, there were 8,674 women and 2,295 men interviewed; and in 2016 there were 18,506 women and 5,336 males interviewed.

\section{Measurements}

Indicators analyzed are in two categories: Maternal and child health outcome indicators, such as infant mortality rate, under-five mortality rate, and child underweight, Child stunting, prevalence of anemia, prevalence of fever, prevalence of Acute Respiratory tract Infections (ARIs), prevalence of diarrhea; in children under five years of age, and Mother's low BMI.

The other category includes indicators of health service use, such as antenatal care, skilled birth attendance, delivery in health facilities, full immunization coverage, medical treatment for child diarrhea, contraceptive prevalence rate, deliveries in government-owned health facilities, medical treatment for ARIs, medical treatment for fever in children under the age of five, and use of ITN.

\section{Data analysis}

Two measures of inequality were used: Quintile ratios, which measure the magnitude of inequality between the wealthiest (highest) and poorest (lowest) quintiles but ignore the middle three quintiles [17].

The Concentration Index is the second metric. This uses data from all five wealth quintiles to provide a complete picture by quantifying the degree of inequalities in the population [18]. The concentration index has a range of -1 to +1 .

Traditionally, if the health status measure is a "bad" in the sense that it depicts poor health, the index takes a negative value, suggesting that the poorest segments of the population bear the largest burden of poor health. If the health status measure is a "good," in the sense that it indicates a positive feature of health, the index takes a positive value, suggesting that the poor are significantly less healthy. In the absence of inequities, the concentration index has a value of zero. The concentration index (C) is calculated in a spreadsheet program from grouped data using the following formula [18].

\section{$\mathrm{C}=(\mathrm{P} 1 \mathrm{~L} 2-\mathrm{P} 2 \mathrm{~L} 1)+(\mathrm{P} 2 \mathrm{~L} 3-\mathrm{P} 3 \mathrm{~L} 2)+\ldots+(\mathrm{PT}-1 \mathrm{LT}-\mathrm{PTLT}-1)$}

Where $\mathrm{P} t$ is the cumulative percent of the sample ranked by wealth status in group $t, \mathrm{~L} t$ is the corresponding Lorenz curve ordinate, and $\mathrm{T}$ is the total number of wealth groups, which is five in this analysis.

\section{Results}

This section begins with findings on maternal and child health outcomes and concludes with results on health-care utilization indicators.

\section{Inequalities in Maternal and Child Health status}

This sub-section presents population averages, quintile ratios and concentration indices for health outcome indicators for all wealth quintiles, rural and urban populations. Table 1 below, summaries the data.

All indicators showed universal improvement across quintiles, and between rural and urban populations. The most success was made in lowering infant and under-five mortality. Between 2006 and 2016, the infant mortality rate fell from 76 to 43 deaths per 1,000 live births, and the under-five mortality rate fell from 137 to 64 deaths per 1,000 live births. All other health status markers showed a similar pattern. 
Table 1

displays population-level health outcome metrics, quintile ratios, and concentration indices from the three surveys.

\begin{tabular}{|c|c|c|c|c|c|c|c|c|c|c|c|c|}
\hline & \multicolumn{4}{|c|}{ Geographical location } & \multicolumn{8}{|c|}{ Wealth Quintiles } \\
\hline $\begin{array}{l}\text { Health } \\
\text { indicators }\end{array}$ & & Rural & Urban & $\begin{array}{l}\text { Low/High } \\
\text { Ratio }\end{array}$ & Lowest & Second & Middle & Fourth & Highest & Total & $\begin{array}{l}\text { Low/High } \\
\text { Ratio }\end{array}$ & $\begin{array}{l}\text { Concentration } \\
\text { Index (CI) }\end{array}$ \\
\hline \multirow{3}{*}{$\begin{array}{l}\text { Infant Mortality } \\
\text { rate (per } 1000 \\
\text { live births) }\end{array}$} & 2006 & 88 & 68 & 1.3 & 102 & 92 & 87 & 80 & 63 & 76 & 1.6 & -0.09 \\
\hline & 2011 & 66 & 54 & 1.2 & 76 & 69 & 64 & 63 & 48 & 54 & 1.6 & -0.08 \\
\hline & 2016 & 57 & 36 & 1.6 & 56 & 50 & 44 & 48 & 39 & 43 & 1.4 & -0.05 \\
\hline \multirow{3}{*}{$\begin{array}{l}\text { Under-five } \\
\text { mortality rate } \\
\text { (per } 1000 \text { live } \\
\text { births) }\end{array}$} & 2006 & 153 & 114 & 1.3 & 172 & 157 & 155 & 140 & 108 & 137 & 1.6 & -0.08 \\
\hline & 2011 & 111 & 77 & 1.4 & 123 & 125 & 100 & 104 & 72 & 90 & 1.7 & -0.10 \\
\hline & 2016 & 68 & 52 & 1.3 & 88 & 79 & 73 & 69 & 53 & 64 & 1.7 & -0.09 \\
\hline \multirow{3}{*}{$\begin{array}{l}\text { Stunting } \\
\text { among children } \\
\text { under age } 5(\%)\end{array}$} & 2006 & 39.5 & 25.5 & 1.5 & 43.4 & 38.0 & 44.4 & 37.6 & 24.3 & 38 & 1.8 & -0.07 \\
\hline & 2011 & 35.6 & 18.6 & 1.9 & 37.3 & 30.9 & 45.0 & 30.5 & 20.8 & 33.4 & 1.8 & -0.07 \\
\hline & 2016 & 30.2 & 23.5 & 1.3 & 32.3 & 33.2 & 33.0 & 27.2 & 16.7 & 28.9 & 1.9 & -0.09 \\
\hline \multirow{3}{*}{$\begin{array}{l}\text { Underweight } \\
\text { among children } \\
\text { under age five } \\
\text { (\%) }\end{array}$} & 2006 & 16.5 & 10.6 & 1.6 & 20.6 & 15.6 & 17.0 & 16.5 & 8.4 & 15.9 & 2.5 & -0.07 \\
\hline & 2011 & 14.9 & 6.6 & 2.3 & 18.1 & 14.3 & 17.3 & 9.5 & 8.4 & 13.8 & 2.2 & -0.14 \\
\hline & 2016 & 11.2 & 7.5 & 1.5 & 15.0 & 11.5 & 11.6 & 8.6 & 4.4 & 10.5 & 3.4 & -0.19 \\
\hline \multirow{5}{*}{$\begin{array}{l}\text { Anemia among } \\
\text { children under } \\
\text { age five }(\%)\end{array}$} & 2006 & 74.3 & 56.6 & 1.3 & 79.7 & 74.8 & 73.3 & 72.3 & 60.5 & 72.6 & 1.3 & -0.04 \\
\hline & 2011 & 50.9 & 38 & 1.3 & 59 & 51.7 & 51 & 42.8 & 38.2 & 49.3 & 1.5 & -0.08 \\
\hline & 2016 & 54 & 47.7 & 1.1 & 65.6 & 54.4 & 48.7 & 48.5 & 44.8 & 52.8 & 1.5 & -0.08 \\
\hline & \multicolumn{4}{|c|}{ Geographical location } & \multicolumn{8}{|c|}{ Wealth Quintile } \\
\hline & & Rural & Urban & $\begin{array}{l}\text { Low/High } \\
\text { Ratio }\end{array}$ & Lowest & Second & Middle & Fourth & Highest & Total & $\begin{array}{l}\text { Low/High } \\
\text { Ratio }\end{array}$ & $\begin{array}{l}\text { Concentration } \\
\text { Index (Cl) }\end{array}$ \\
\hline \multirow{3}{*}{$\begin{array}{l}\text { Diarrhea } \\
\text { among children } \\
\text { under age five } \\
(\%)\end{array}$} & 2006 & 26.5 & 19.7 & 1.3 & 33.7 & 27.2 & 23.6 & 23.6 & 18.1 & 25.8 & 1.9 & -0.11 \\
\hline & 2011 & 23.7 & 21.8 & 1.1 & 28.8 & 25.2 & 21.8 & 20.6 & 19.5 & 23.4 & 1.5 & -0.08 \\
\hline & 2016 & 20.2 & 17 & 1.2 & 22.2 & 21 & 19.2 & 18.1 & 16.5 & 19.5 & 1.3 & -0.05 \\
\hline \multirow{3}{*}{$\begin{array}{l}\text { ARI among } \\
\text { children under } \\
\text { age five (\%) }\end{array}$} & 2006 & 15 & 10.7 & 1.4 & 18.7 & 16.8 & 13.8 & 12.2 & 8.9 & 14.5 & 2.1 & -0.13 \\
\hline & 2011 & 15.2 & 13 & 1.2 & 20.1 & 16.5 & 12.6 & 12.1 & 11.9 & 14.8 & 1.7 & -0.11 \\
\hline & 2016 & 10.1 & 7.1 & 1.4 & 12.7 & 10.5 & 9 & 8.3 & 5.5 & 9.3 & 2.3 & -0.14 \\
\hline \multirow{3}{*}{$\begin{array}{l}\text { Fever among } \\
\text { children under } \\
\text { age five (\%) }\end{array}$} & 2006 & 43 & 25 & 1.7 & 48.3 & 44.7 & 37.1 & 39.2 & 32.5 & 40.9 & 1.5 & -0.06 \\
\hline & 2011 & 42.1 & 30.3 & 1.4 & 49.8 & 42.6 & 36.8 & 40.7 & 30.3 & 40.4 & 1.6 & -0.09 \\
\hline & 2016 & 36.4 & 22 & 1.7 & 43.9 & 37 & 32.6 & 31.2 & 19.6 & 33.3 & 2.2 & -0.13 \\
\hline \multirow{3}{*}{$\begin{array}{l}\text { Mothers' low } \\
\text { BMI }\end{array}$} & 2006 & 13.5 & 5.9 & 2.3 & 23.2 & 15.1 & 12.3 & 8.6 & 5.9 & 12.1 & 3.9 & -0.26 \\
\hline & 2011 & 12.9 & 7.6 & 1.7 & 22.8 & 18.3 & 9 & 7.6 & 5.9 & 11.7 & 3.9 & -0.29 \\
\hline & 2016 & 9.3 & 6.9 & 1.3 & 16.9 & 10.9 & 8.9 & 5.4 & 4.3 & 8.7 & 3.9 & -0.28 \\
\hline
\end{tabular}

\section{i. Changes in absolute terms}

The poorest group improved more than the wealthiest group. From 2006 to 2016, there was an absolute decrease in under-five mortality in the lowest quintile of 84 deaths per 1,000 live births. However, in terms of anaemia and fever prevalence, the lowest quintile group improved less than the richest group.

The rural population improved at a faster rate than the urban population. Under-five mortality, for example, fell by 85 deaths per 1000 live births in rural areas compared to 62 deaths per 1000 live births in urban areas. Stunting prevalence decreased by 9 percentage points in rural areas but only by 2 percentage points in urban areas. 


\section{ii. Quintile Ratios}

Data analysis utilizing quintile ratios reveals that there is inequality between the poorest and richest quintiles. All of the variables have quintile ratios greater than one, showing the presence of inequalities that favor the wealthy over the poor. Furthermore, the quintile ratios rose with time in most indices, showing a growing inequality gap between the rich and the poor.

The ratios of the lowest (poorest) to highest (wealthiest) quintiles, as well as rural to urban ratios, are shown in Table 1.

The greatest ratios, and therefore bigger disparities, were reported in the under-five mortality rate, child stunting, underweight in children, prevalence of anaemia in children, prevalence of ARI, prevalence of fever, and mothers with low BMI. For example, the frequency of underweight in children among the poorest was 2.5 times greater in 2006 than among the wealthiest, and 3.4 times higher in 2016. A similar pattern may be seen for the prevalence of fever in children, the prevalence of ARI, the prevalence of anaemia in children, and the prevalence of child stunting. The prevalence of low BMI among mothers remained extraordinarily high, at 3.9 across the board.

Except for infant mortality rate, all indices show dropping quintile ratios for rural vs. urban populations from 2006 to 2016 . This finding depicts shrinking disparities between rural and urban populations.

\section{iii. Concentration Indices}

First, all of the concentration indices for health outcome indicators were negative, indicating that the poor are more afflicted by illness. Second, with the exception of the infant mortality rate and the incidence of diarrhea, all indicators showed increasing concentration indices.

For example, the concentration index for childhood underweight grew from - 0.07 in 2006 to -0.19 in 2016 . Rising concentration indices suggest that inequality gaps are widening, against persons with low socioeconomic status.

\section{Inequalities in the Utilization of Maternal and Child Health Services}

At the population level, there has been a consistent and significant increase in all measures of service consumption, for all quintile groups, rural and urban populations. For example, the proportion of births attended by a skilled birth attendant increased from $42 \%$ in 2006 to $74 \%$ in 2016 .

Contraceptive prevalence has increased from 18\% in 2006 to $35 \%$ in 2016 . Figures 3 and 4 depict graphical representations of absolute changes for socioeconomic quintiles and rural vs. urban areas, respectively. 
Table 2

displays population-level maternal and child health service metrics, quintile ratios, and concentration indices from the three surveys.

\section{Wealth Quintile}

\begin{tabular}{|c|c|c|c|c|c|c|c|c|c|c|c|c|}
\hline $\begin{array}{l}\text { Health } \\
\text { indicators }\end{array}$ & & Rural & Urban & $\begin{array}{l}\text { Urban/Rural } \\
\text { Ratio }\end{array}$ & Lowest & Second & Middle & Fourth & Highest & Total & $\begin{array}{l}\text { High/Low } \\
\text { Ratio }\end{array}$ & $\begin{array}{l}\text { Concentration } \\
\text { Index (CI) }\end{array}$ \\
\hline \multirow{3}{*}{$\begin{array}{l}\text { Births } \\
\text { assisted by } \\
\text { skilled birth } \\
\text { attendant (\%) }\end{array}$} & 2006 & 37.3 & 80 & 2.1 & 28.4 & 31.7 & 35 & 49.1 & 76.6 & 42.1 & 2.7 & 0.19 \\
\hline & 2011 & 52.8 & 89.1 & 1.7 & 43.5 & 48.9 & 54.4 & 59.6 & 88.4 & 58 & 2.0 & 0.12 \\
\hline & 2016 & 70 & 89.9 & 1.3 & 64.3 & 64.3 & 71.7 & 79.3 & 94.1 & 74.2 & 1.5 & -0.72 \\
\hline \multirow{3}{*}{$\begin{array}{l}\text { Births } \\
\text { delivered in } \\
\text { health facility } \\
(\%)\end{array}$} & 2006 & 36.3 & 78.7 & 2.2 & 27.4 & 30.9 & 33.9 & 47.9 & 75.5 & 41.1 & 2.8 & 0.20 \\
\hline & 2011 & 52 & 89.5 & 1.7 & 42.2 & 48.9 & 54.4 & 58.4 & 87.7 & 57.4 & 2.1 & 0.12 \\
\hline & 2016 & 69.5 & 87.8 & 1.3 & 64.2 & 63.1 & 70.7 & 79 & 92.7 & 73.4 & 1.4 & -0.72 \\
\hline \multirow{3}{*}{$\begin{array}{l}\text { Births } \\
\text { delivered in } \\
\text { government } \\
\text { health facility } \\
\text { (\%) }\end{array}$} & 2006 & 25.6 & 57 & 2.2 & 21.3 & 23.1 & 25.1 & 32.2 & 50 & 29.1 & 2.3 & 0.17 \\
\hline & 2011 & 40.8 & 63.5 & 1.6 & 37.2 & 39.1 & 43.6 & 42.7 & 59.7 & 44 & 1.6 & 0.08 \\
\hline & 2016 & 55.7 & 63.2 & 1.1 & 56 & 53.1 & 58 & 59.7 & 60.4 & 57.3 & 1.1 & -0.78 \\
\hline \multirow{3}{*}{$\begin{array}{l}\text { Children 12- } \\
23 \text { months } \\
\text { fully } \\
\text { immunized } \\
(\%)\end{array}$} & 2006 & 45.7 & 51.1 & 1.1 & 41.4 & 45.0 & 48.2 & 49.3 & 47.9 & 46.2 & 1.2 & 0.03 \\
\hline & 2011 & 50.2 & 60.8 & 1.2 & 50.6 & 51.4 & 48.7 & 52.6 & 54.9 & 51.6 & 1.1 & 0.01 \\
\hline & 2016 & 54.5 & 55.5 & 1.0 & 56.1 & 54.7 & 55.9 & 55.2 & 54.3 & 55.2 & 1.0 & -0.77 \\
\hline \multirow{4}{*}{$\begin{array}{l}\text { Children } \\
\text { under five } \\
\text { years with } \\
\text { diarrhea that } \\
\text { received } \\
\text { medical } \\
\text { treatment (\%) }\end{array}$} & 2006 & 70.3 & 68.9 & 1.0 & 77.6 & 69.6 & 61.3 & 67.8 & 70.5 & 70.2 & 0.9 & -0.03 \\
\hline & 2011 & 72.7 & 70.2 & 1.0 & 73.7 & 72.5 & 74.4 & 72.7 & 67.1 & 72.4 & 0.9 & -0.02 \\
\hline & 2016 & 70.6 & 70.2 & 1.0 & 73.5 & 69.6 & 69.3 & 68.2 & 70.8 & 70.5 & 1.0 & -0.85 \\
\hline & & Rural & Urban & $\begin{array}{l}\text { Urban/Rural } \\
\text { Ratio }\end{array}$ & Lowest & Second & Middle & Fourth & Highest & Total & $\begin{array}{l}\text { High/Low } \\
\text { Ratio }\end{array}$ & $\begin{array}{l}\text { Concentration } \\
\text { Index (Cl) }\end{array}$ \\
\hline \multirow{3}{*}{$\begin{array}{l}\text { Contraceptive } \\
\text { prevalence } \\
\text { rate (\%) }\end{array}$} & 2006 & 15.1 & 36.5 & 2.4 & 7.2 & 12.1 & 13.1 & 20.3 & 37.9 & 17.9 & 5.3 & 0.09 \\
\hline & 2011 & 23.4 & 39.2 & 1.7 & 12.7 & 21.2 & 24.7 & 31.0 & 39.1 & 26.0 & 3.1 & 0.20 \\
\hline & 2016 & 33.0 & 40.7 & 1.2 & 22.4 & 32.2 & 35.9 & 40.2 & 42.2 & 34.8 & 1.9 & -0.67 \\
\hline \multirow{3}{*}{$\begin{array}{l}\text { Children } \\
\text { under five } \\
\text { years with } \\
\text { ARI, that } \\
\text { received } \\
\text { medical } \\
\text { treatment (\%) }\end{array}$} & 2006 & 73.7 & 68.3 & 0.9 & 79.5 & 67.7 & 69.8 & 72.8 & 77.5 & 73.3 & 1.0 & -0.01 \\
\hline & 2011 & 78.4 & 80.8 & 1.0 & 77.8 & 78.9 & 78.1 & 77.2 & 82.3 & 78.7 & 1.1 & 0.00 \\
\hline & 2016 & 80.0 & 82.6 & 1.0 & 79.7 & 77.6 & 78.2 & 84.5 & 85.8 & 80.4 & 1.1 & -0.86 \\
\hline \multirow{3}{*}{$\begin{array}{l}\text { Antenatal } \\
\text { visits to a } \\
\text { trained } \\
\text { personnel (\%) }\end{array}$} & 2006 & 93 & 97.2 & 1.0 & 93.2 & 92.3 & 92.9 & 93.2 & 96.4 & 93.5 & 1.0 & 0.00 \\
\hline & 2011 & 94.4 & 97.4 & 1.0 & 93.9 & 94.5 & 94.3 & 94.5 & 97.1 & 94.9 & 1.0 & -0.08 \\
\hline & 2016 & 97.1 & 98.1 & 1.0 & 96.0 & 96.9 & 98.3 & 97.3 & 98.1 & 97.3 & 1.0 & -0.79 \\
\hline \multirow{3}{*}{$\begin{array}{l}\text { Insecticide- } \\
\text { treated net } \\
\text { (ITN) use in } \\
\text { Children } \\
\text { under } 5 \text { years } \\
(\%)\end{array}$} & 2006 & 8.3 & 21.3 & 2.6 & 10.7 & 9.7 & 4.9 & 8.8 & 15.4 & 9.7 & 1.4 & 0.04 \\
\hline & 2011 & 41.9 & 48.9 & 1.2 & 44.8 & 40.7 & 39 & 41.3 & 48.6 & 42.2 & 1.1 & 0.01 \\
\hline & 2016 & 67.0 & 60.8 & 0.9 & 57.8 & 58.2 & 59.1 & 64.3 & 72.8 & 62 & 1.3 & -0.77 \\
\hline \multirow{3}{*}{$\begin{array}{l}\text { Children } \\
\text { under five } \\
\text { years with } \\
\text { fever that } \\
\text { received } \\
\text { medical } \\
\text { treatment (\%) }\end{array}$} & 2006 & 74.5 & 76.8 & 1.0 & 78.1 & 72.0 & 72.0 & 72.3 & 80.0 & 74.7 & 1.0 & 0.00 \\
\hline & 2011 & 79.2 & 87.2 & 1.1 & 78.8 & 79.1 & 82.3 & 77.6 & 84.5 & 80.1 & 1.1 & 0.01 \\
\hline & 2016 & 55.0 & 47.3 & 0.9 & 46.6 & 45.3 & 45.3 & 49.4 & 62.8 & 48.4 & 1.3 & -0.84 \\
\hline
\end{tabular}


For all variables, absolute gains are bigger among the lowest quintile (poorest) than among the wealthiest, with the exception of ITN use among children under five years and fever and ARI treatment for children under five years. The increases in the poorest group for skilled birth attendants at delivery (SBA) and facility deliveries are twice as large as the increases in the wealthiest group.

Except for diarrhea and ARI treatment, the rural population experienced greater absolute increases than the urban population in all variables.

The improvements in rural populations' usage rates for skilled birth attendants at delivery (SBA), facility deliveries, ITN use, and contractive use were at least twice as large as the changes in urban populations' usage rates.

\section{ii. Quintile Ratios}

Despite significant improvements in health-care utilization among the poorest households, socioeconomic inequities were discovered. This is demonstrated by quintile ratios greater than one, as seen in Table 2 above.

However, the ratios for all variables fell with time, indicating shrinking differences between the richest and poorest populations. The quintile ratio for facility deliveries, for example, declined from 2.8 in 2006 to 1.4 in 2016 . A similar pattern can be seen for the contraceptive prevalence rate as well as all other measures.

Despite significant improvements in rural health-care utilization, rural-urban disparities were discovered. This finding was supported by quintile ratios greater than one in the majority of the services, as seen in Table 2 above. The high quintile ratios suggest that the urban population uses more services than the rural population. However, quintile ratios decreased with time, indicating that inequality was shrinking. The quintile ratio of health facility deliveries, for example, fell from 2.2 in 2006 to 1.3 in 2016.

\section{iii. Concentration Indices}

Except for diarrhoea treatment, all indicators exhibited positive concentration indices in 2006 and 2011, before changing to negative levels in 2016. This demonstrates a shift from a pro-rich inequality to a more equitable one (pro-poor). For example, facility birth indices fell from 0.20 in 2006 to 0.12 in 2011 to -0.72 in 2016.

\section{Discussion}

The following metrics revealed worsening socioeconomic and rural-urban disparities.

\section{Under-five mortality rate (per 1000 live births).}

Data analysis reveals a growing inequality gap between the poorest and wealthiest quintiles, as shown by a rise in quintile ratio from 1.6 in 2006 to 1.7 in 2016, as well as an increasing concentration index from - 0.08 in 2006 to -0.09 . A similar pattern was discovered in both rural and urban groups. In a previous study, [19] discovered inequalities in under-five and infant mortality rates that disadvantaged poorer households. Child mortality in SubSaharan Africa is linked to economic inequality, and not just epidemiological reasons [20].

\section{Malnutrition among children under the age of five.}

The child malnutrition characteristics of stunting (low height for age) and underweight (low weight for age) revealed a widening socioeconomic disparity gap. The highest disparity was seen in the Under-weight parameter.

Similarly, [21] discovered socioeconomic gaps in child malnutrition in a prior study, with Underweight exhibiting greater inequalities than Stunting. Furthermore, [22] proved that malnutrition inequalities affect the poor; malnutrition diminishes consistently with growing living standards, and inequalities in underweight tend to be bigger than discrepancies in overweight.

However, there has been a decline in inequality between rural and urban areas for both underweight and stunting. This conclusion coincides with [23], who found that the rural-urban divide in child malnutrition was modest in some countries.

\section{Anaemia prevalence in children under the age of five years.}

This study discovered rising socioeconomic inequality gaps that disproportionately affect the poorest children. This is supported by an increase in quintile ratios (from 1.3 in 2006 to 1.5 in 2016), as well as an increase in the concentration index from - 0.04 in 2006 to -0.08 in 2016 . In a prior study, [24] discovered a higher risk of anaemia in children from low socioeconomic backgrounds, as well as in rural moms and their children. Similarly, [25] discovered that the prevalence of anemia in children under the age of five was lower in affluent households than in poorer households. 


\section{Acute Respiratory Tract Infection (ARI) in children under the age of five.}

A rising trend of inequality against the poor has been detected. This was demonstrated by an increase in quintile ratios from 2.1 in 2006 to 2.3 in 2016 , as well as an increase in concentration indices from - 0.13 in 2006 to -0.14 in 2016 . A similar tendency was noted between rural and urban areas, with disparity favoring urban residents. In a similar vein, [26] discovered that children from the poorest quintile were 2.36 times more likely to suffer from ARIs than children from the richest quintile; and the likelihood of seeking care was lower for children from the poorest quintile than for children from the richest quintile.

\section{Fever prevalence in children under the age of five.}

Growing quintile ratios from 1.5 in 2006 to 2.2 in 2016 revealed widening socioeconomic disparity between the richest and poorest groups, which was verified by rising concentration indices from -0.06 in 2006 to -0.13 in 2016 . There is also growing disparity between rural and urban households. In a previous study, [27] proved in a prior study that fever occurrences are often lower at the very top of the wealth distribution and treatment practices are associated to poverty in Sub-Saharan Africa.

\section{Mothers with a low Body Mass Index (BMI).}

It was discovered that there is a growing disparity in mothers' nutritional condition against the poor. From 2006 to 2016 , quintile ratios stayed constant at 3.9, while concentration indices increased from -0.26 in 2006 to -0.28 in 2016.

The quintile ratios declined from 2.3 in 2006 to 1.3 in 2016, indicating a shrinking inequality gap between rural and urban areas. In a earlier study, [28] discovered considerable variations in maternal under-nutrition, significantly favoring higher socioeconomic groups in a previous study. Socioeconomic characteristics were also found to be highly related with maternal under-nutrition [29]. On the other hand, [30] discovered that maternal malnutrition was concentrated among the rural population.

The following measures, on the other hand, showed that socioeconomic and rural-urban disparities were reducing or improving.

\section{Rate of Infant Mortality (per 1000 live births).}

There has been a decrease in socioeconomic disparity. This was demonstrated by falling quintile ratios, which fell from 1.6 in 2006 to 1.4 in 2016 , as well as a falling concentration index, which fell from - 0.09 in 2006 to -0.05 in 2016.

However, a growing disparity has been discovered between rural and urban households (quintile ratios from 1.3 to 1.6). Similarly, [31] discovered a declining socioeconomic inequality trend in India's infant mortality rate. In addition, [32] discovered that rural areas have significantly higher rates of infant mortality than urban areas.

\section{Diarrhea prevalence in children under the age of five.}

This indicator has a lowering socioeconomic inequality trend (ratio dropped from 1.9 to 1.3), which is supported by a drop in concentration index from 0.11 in 2006 to -0.05 in 2016. A similar pattern was noticed in both rural and urban locations (ratio reduced from 1.3 to 1.2). In contrast to this finding [33] discovered that rural areas have greater probabilities of diarrhoea than non-rural areas, and that neighbourhood socioeconomic status and household wealth status are the key drivers to the inequality.

\section{The proportion of births attended by skilled birth attendants.}

This study found that this indicator's socioeconomic and rural-urban inequality gaps were closing, resulting in a virtually perfect equity position. Quintile ratios decreased dramatically from 2.7 in 2006 to 1.5 in 2016, and supported by a negative concentration index of -0.72 in 2016 . In a recent study, [34] discovered diminishing gaps in skilled birth attendant utilization among socioeconomic categories. According to [35], rural-urban disparities in the use of prenatal care and skilled birth attendants are narrowing.

\section{The proportion of births that take place in a health facility.}

This indicator revealed a downward trend in socioeconomic and rural-urban inequality. This is supported by falling quintile ratios, which fell from 2.8 in 2006 to 1.4 in 2016, as well as falling concentration indices, which fell from 0.20 in 2006 to -0.72 in 2016 . The trend of inequality has shifted to a more egalitarian stance (pro-poor). In contrast [36] found widening disparities in the utilization of institutional delivery services based on wealth and place of residence, favoring urban rich women. 


\section{The percentage of births that take place at a government health facility.}

Similarly, there is a shrinking socioeconomic and rural-urban inequality divide. By 2016, the tendency had reversed to about complete equity. Quintile ratios fell from 2.3 to 1.1 in 2016, and the concentration index fell to -0.78 . in a previous study, [36] found that women from low-income families and rural communities used public facilities more frequently. On the other hand [37] discovered a pro-rich disparity in the use of public health services.

\section{Percentage of children aged 12 to 23 months who are fully vaccinated.}

This indicator revealed a downward trend in socioeconomic and rural-urban inequality. Quintile ratios fell from 1.2 to 1.0 in 2016 , with a concentration index of -0.77 indicating a nearly ideal equity position. In a prior study, [38] discovered that disadvantaged children had higher vaccine coverage than those from the highest socioeconomic stratum. On the contrary, [39] discovered that higher socioeconomic position households are more likely than lower socioeconomic status families to have their children inoculated.

\section{Diarrhea treatment for children under the age of five.}

In this measure, a fully perfect equity situation was established between the poor and the rich; rural and urban. Quintile ratios less than one and concentration indices with negative values demonstrated this. On the other hand [40] discovered that wealthier households were more likely than poorer ones to seek medical treatment for childhood diarrhea. In a similar way, [41] discovered that rural inhabitants are less likely to report diarrhoea than urban residents, and that the rural poor had higher chances of diarrhoea occurrence than the rich.

\section{Contraceptive prevalence rate (\%).}

A downward tendency in socioeconomic inequality between rural and urban areas has been documented. The quintile levels decreased dramatically from 5.3 in 2006 to 1.9 in 2016. This finding was backed up by a drop in the concentration index from 0.09 in 2006 to -0.67 in 2016 , indicating a nearly ideal equity position. According to [42], there is rising equality in the use of contemporary contraceptives, and the rural-urban divide in the use of modern contraceptive techniques has practically vanished. On the other hand, [43] found that women in poor communities were less likely to use modern contraception than women in wealthy communities.

\section{Medical treatment for ARI symptoms in children under the age of five.}

This indicator identified an absolutely flawless equity position. Quintile ratios were equivalent to one, with negative concentration indices ranging from - 0.01 to -0.86 . Rural and urban populations were found to be in a comparable position. In contrast to this conclusion, [14] discovered that access to COPD treatment was stronger in urban regions than in rural areas. More so, [44] found that rural living was significantly associated with acute respiratory infection.

\section{ITN usage among children under five years of age.}

A almost perfect equity position was discovered, as shown by quintile ratios falling from 1.4 in 2006 to 1.3 in 2016 , and the diminishing concentration index falling from 0.04 in 2006 to -0.77 in 2016. In contrast, [45] discovered that the rich were more likely than the poor to own and use ITNs.

\section{Fever treatment in children under the age of five.}

Likewise, a fully flawless equity position was discovered. Quintile ratios of 1 and concentration indexes of 0.00 in 2006 and -0.84 in 2016 attest to this. In contrast, [46] discovered that socioeconomic factors have a significant impact on the use of medical therapy for pediatric illnesses. Furthermore, [40] discovered that wealthier households were more likely than poor households to seek medical treatment for children fever.

\section{Conclusion}

In majority of the measures, the results show a significant improvement in population averages. The rises are universal, ranging from the lowest to the wealthiest groups, as well as between rural and urban areas.

Significant socioeconomic and rural-urban disparities persist. Under-five mortality, malnutrition in children (Stunting and Underweight), the prevalence of anaemia in children, mothers' low BMI, and the prevalence of ARI in children were all found to have worsening inequities.

Improving or lowering disparity levels toward a perfect equity stance were mostly identified in healthcare use indicators such as skilled birth attendants, facility delivery, contraceptive prevalence rate, child immunization, diarrhea treatment, and ITN use. Three healthcare use measures, namely medical 
treatment for diarrhea, medical treatment for ARI symptoms, and medical treatment for fever in children under the age of five, demonstrated a perfectly flawless equity situation.

\section{Recommendation}

Intervention initiatives should prioritize the impoverished and rural communities while also considering the rich and urban portions of the community.

\section{Abbreviations}

ARI : Acute Respiratory tract Infections
BMI : Body Mass Index
CDC: Center for Disease Control
COPD : Chronic Obstructive Pulmonary Disease
DHS : Demographic and health Survey
GDP : Gross Domestic Product
HDI : Human Development Index
SBA : Skilled Birth Attendants
UBOS : Uganda Bureau of Statistics
UNDP : United Nations Development Program
USD : United States Dollars
WHO : World Health Organisation

\section{Declarations}

\section{Ethics approval and consent to participate}

Because the data is secondary and in the public domain, no ethics approval was required for this study. Because there are no primary respondents in this study, consent to participate was not required.

\section{Consent for publication}

Demographic and Health Survey is an open-source dataset that has been de-identified. As a result, the consent for publication requirement is not applicable.

\section{Competing interests}

The author declares no competing interests.

\section{Author details}

The author is a PhD student at Bishop Stuart University.

\section{Acknowledgements}

I would like to thank my teachers, Dr. Kahyana Danson, and Prof. Roberts K. Muriisa for their teaching, encouragement and advice on research and scholarly writing. The author is solely responsible for any errors of omission or commission.

\section{Funding}

This research received no grant from any funding agency in the public, commercial, or not-for-profit sectors.

\section{Availability of data and materials}


The datasets analyzed during this study are available in the Uganda Bureau of Statistics (UBOS) repository, available at: https://www.ubos.org/? pagename=explore-publications\&p_id=25

\section{References}

1. WHO (2005): Priorities for research to take forward the health equity policy agenda. Geneva 2004. Bulletin of the World Health Organization; 83:948953. [Online]. https://www.who.int/bulletin/volumes/83/12/948.pdf?

ua=1\#: :text=We\%20recommend\%20that\%20highest\%20priority,and\%20relationships\%20that\%20differentially\%20affect.

2. Gwatkin D.R (2001) The need for equity-oriented health sector reforms, International Journal of Epidemiology: 30:720-723., https://doi.org/10.1093/ije/30.4.720

3. Bonfrer, I., Van de Poel, E., Grimm.M., Van Doorslaer,E.,(2014). Does the distribution of healthcare utilization match needs in Africa?, Health Policy and Planning, Volume 29, Issue 7, Pages 921-937, https://doi.org/10.1093/heapol/czt074.

4. Gwatkin. D.R., Bhuyia. A., Victora. C.G.,(2004). Making health systems more equitable. The Lancet 2004, 364:1273-1280. doi: 10.1016/S01406736(04)17145-6.

5. Ataguba J. E., and Alaba, O., (2012). Explaining health inequalities in South Africa: A political economy perspective. Development Southern Africa, 29:5, 756-764, DOI: 10.1080/0376835X .2012.730962

6. Kiwanuka, S. N., Ekirapa, E. K., Peterson, S., Okui, O., Rahman, M. H., Peters, D., \& Pariyo, G. W. (2008). Access to and utilisation of health services for the poor in Uganda: a systematic review of available evidence. Transactions of the Royal Society of Tropical Medicine and Hygiene, 102(11), 10671074. https://doi.org/10.1016/j.trstmh.2008.04.023

7. Ssewanyana, S., \& Kasirye, I. (2012). Causes of health inequalities in Uganda: evidence from the demographic and health surveys. African Development Review, 24(4), 327-341. Doi: https://doi.org/10.1111/1467-8268.12007

8. Pittman P.M., (2006). Beyond the sound of one hand clapping: experiences in six countries using health equity research in policy. Journal of Health Politics, Policy \& Law. 2006; 31(1):33-49. doi: 10.1215/03616878-31-1-33.

9. Ward, P. (2009). The relevance of equity in health care for primary care: creating and sustaining a 'fair go, for a fair innings' Quality in Primary Care 2009;17. PMID: 19281674

10. Braveman and Gruskin (2003). Defining equity in health. Journal of Epidemiology and Community Health 2003;57:254-258. http://dx.doi.org/10.1136/jech.57.4.254

11. Uganda Bureau of Statistics - UBOS. (2016). The National Population and Housing Census 2014 - Main Report, Kampala, Uganda. Available at. https://www.ubos.org/wp-content/uploads/publications/03_20182014_National_Census_Main_Report.pdf.

12. UNDP (2020). Human Development Report 2020. The next frontier. Human development and the Anthropocene. UN Plaza, New York. http://hdr.undp.org/sites/default/files/hdr_2020_overview_english.pdf

13. World Bank (2016). The Uganda Poverty Assessment Report. Report No. ACS18391. The World Bank Group. https://pubdocs.worldbank.org/en/381951474255092375/pdf/Uganda-Poverty-Assessment-Report-2016.pdf.

14. Robertson, N. M., Nagourney, E. M., Pollard, S. L., Siddharthan, T., Kalyesubula, R., Surkan, P. J., Hurst, J. R., Checkley, W., \& Kirenga, B. J. (2019). Urban-Rural Disparities in Chronic Obstructive Pulmonary Disease Management and Access in Uganda. Chronic obstructive pulmonary diseases (Miami, Fla.), 6(1), 17-28. https://doi.org/10.15326/jcopdf.6.1.2018.0143

15. McLeroy, K.R., Bibeau, D., Steckler, A., Glanz, K.,(1988). An ecological perspective on health promotion programs. Health Educ Q. 1988 Winter;15(4):351-77. doi: 10.1177/109019818801500401. https://pubmed.ncbi.nlm.nih.gov/3068205/.

16. Golden, S. D., \& Earp, J. A. L. (2012). Social ecological approaches to individuals and their contexts: twenty years of health education \& behavior health promotion interventions. Health education \& behavior, 39(3), 364-372. https://doi.org/10.1177/1090198111418634.

17. Mangham, L. (2009) ACT Consortium Guidance on Health Equity Analysis. Available at www.actconsortium.org/healtheconomicsguidance

18. O'Donnell, O., van Doorslaer, E., Wagstaff, A., Lindelow, M., (2008). .Analyzing health equity using household survey data : a guide to techniques and their implementation. The International Bank for Reconstruction and Development / The World Bank.

19. Wagstaff, A. (2000). Socioeconomic inequalities in child mortality: comparisons across nine developing countries. Bulletin of the World Health Organization, 78, 19-29. [Online]. https://www.scielosp.org/article/ssm/content/raw/? resource_ssm_path=/media/assets/bwho/v78n1/v78n1a03.pdf.

20. Brockerhoff, M., \& Hewett, P. (2000). Inequality of child mortality among ethnic groups in subSaharan Africa. Bulletin of the World Health Organization, 78, 30-41. [Online].https://www.scielosp.org/article/ssm/content/raw/? resource_ssm_path=/media/assets/bwho/v78n1/v78n1a04.pdf. [Accessed on 6/7/2021].

21. Novignon, J., Aboagye, E., Agyemang, O.S. et al.,(2015). Socioeconomic-related inequalities in child malnutrition: evidence from the Ghana multiple indicator cluster survey. Health Econ Rev 5, 34. https://doi.org/10.1186/s13561-015-0072-4 
22. Wagstaff, A., and Watanabe, N. (2000). Socioeconomic inequalities in child malnutrition in the developing world. World Bank Policy Research Working Paper, (2434). https://papers.ssrn.com/sol3/papers.cfm?abstract_id=2894709.

23. Sharaf, M.F., and Rashad, A.S.(2016). Regional inequalities in child malnutrition in Egypt, Jordan, and Yemen: a Blinder-Oaxaca decomposition analysis. Health Econ Rev 6, 23. https://doi.org/10.1186/s13561-016-0097-3

24. Alaofè, H., Burney, J., Naylor, R., \& Taren, D. (2017). Prevalence of anaemia, deficiencies of iron and vitamin A and their determinants in rural women and young children: A cross-sectional study in Kalalé district of northern Benin. Public Health Nutrition, 20(7), $1203-1213$. doi:10.1017/S1368980016003608

25. Ekholuenetale, M., Tudeme, G., Onikan, A. et al (2020). Socioeconomic inequalities in hidden hunger, undernutrition, and overweight among underfive children in 35 sub-Saharan Africa countries. J. Egypt. Public. Health. Assoc. 95, 9 (2020). https://doi.org/10.1186/s42506-019-0034-5

26. Sultana M, Sarker AR, Sheikh N, Akram R, Ali N, Mahumud RA, et al. (2019) Prevalence, determinants and health care-seeking behavior of childhood acute respiratory tract infections in Bangladesh. PLoS ONE 14(1): e0210433. https://doi.org/10.1371/journal.pone.0210433

27. Filmer,D.(2005). Fever and its treatment among the more and less poor in sub-Saharan Africa, Health Policy and Planning, Volume 20 , Issue 6. Pages 337-346, https://doi.org/10.1093/heapol/czi043

28. Geda, N. R. (2021). Inequalities in maternal malnutrition in Ethiopia: evidence from a nationally representative data. BMC Women's Health, 21(1), 110. https://doi.org/10.1186/s12905-020-01154-8

29. Lombamo, G. E., Henry, C. J., Regassa, N., \& Zello, G. A. (2016). Child stunting and maternal undernutrition in two rural Ethiopian communities five years after the initiation of the National Nutrition Program. The FASEB Journal, 30,669-4. https://doi.org/10.1096/fasebj.30.1_supplement.669.4

30. Omilola, B. (2010). Patterns and trends of child and maternal nutrition inequalities in Nigeria (No. 968). International Food Policy Research Institute (IFPRI). IFPRI Discussion Paper 00968 http://citeseerx.ist.psu.edu/viewdoc/download?doi=10.1.1.226.7040\&rep=rep1\&type=pdf.

31. Hosseinpoor, A. R., Mohammad, K., Majdzadeh, R., Naghavi, M., Abolhassani, F., Sousa, A., ... \& Vega, J. (2005). Socioeconomic inequality in infant mortality in Iran and across its provinces. Bulletin of the World Health Organization, 83, 837-844.

https://www.scielosp.org/article/ssm/content/raw/?resource_ssm_path=/media/assets/bwho/v83n11/v83n11a13.pdf.

32. Kumar, A., Singh, A (2014). Is Economic Inequality in Infant Mortality Higher in Urban than in Rural India?. Matern Child Health Journal: 18, pp 2061-2070. https://doi.org/10.1007/s10995-014-1452-9

33. Fagbamigbe, A.F., Oyinlola, F.F., Morakinyo, O.M. et al. Mind the gap: what explains the rural-nonrural inequality in diarrhoea among under-five children in low and medium-income countries? A decomposition analysis. BMC Public Health 21, 575 (2021). https://doi.org/10.1186/s12889-02110615-0

34. Kengia, J. T., Igarashi, I., \& Kawabuchi, K. (2013). Effectiveness of health sector reforms in reducing disparities in utilization of skilled birth attendants in Tanzania. The Tohoku journal of experimental medicine, 230(4), 241-253.

35. Asamoah, B.O., Agardh, A., Pettersson, K.O. et al (2014). Magnitude and trends of inequalities in antenatal care and delivery under skilled care among different socio-demographic groups in Ghana from 1988 - 2008. BMC Pregnancy Childbirth 14, 295 (2014). https://doi.org/10.1186/14712393-14-295

36. Hasan, M. M., Magalhaes, R. J. S., Fatima, Y., Ahmed, S., \& Mamun, A. A. (2021). Levels, trends, and inequalities in using institutional delivery services in low-and middle-income countries: a stratified analysis by facility type. Global Health: Science and Practice, 9(1), 78-88.

37. Phiri, J.,and Ataguba, J.E.,(2014) Inequalities in public health care delivery in Zambia. Int J Equity Health 13, 24. https://doi.org/10.1186/14759276-13-24

38. Barata, R. B., de Almeida Ribeiro, M. C. S., de Moraes, J. C., Flannery, B., \& Vaccine Coverage Survey 2007 Group. (2012). Socioeconomic inequalities and vaccination coverage: results of an immunisation coverage survey in 27 Brazilian capitals, 2007-2008. J Epidemiol Community Health, 66(10), 934-941. http://dx.doi.org/10.1136/jech-2011-200341.

39. Chigwenah, T. (2020). Explaining the socio-economic inequalities in child immunisation coverage in Zimbabwe (Master's thesis, University of Cape Town).

40. Ayalneh, A. A., Fetene, D. M., \& Lee, T. J. (2017). Inequalities in health care utilization for common childhood illnesses in Ethiopia: evidence from the 2011 Ethiopian Demographic and Health Survey. International journal for equity in health, 16(1), 1-9. https://doi.org/10.1186/s12939-017-0561-7.

41. Kumi-Kyereme, A., \& Amo-Adjei, J. (2016). Household wealth, residential status and the incidence of diarrhoea among children under-five years in Ghana. Journal of epidemiology and global health, 6(3), 131-140. https://doi.org/10.1016/j.jegh.2015.05.001

42. Asamoah, B. O., Agardh, A., \& Östergren, P. O. (2013). Inequality in fertility rate and modern contraceptive use among Ghanaian women from 19882008. International journal for equity in health, 12(1), 1-12. DOlhttps://doi.org/10.1186/1475-9276-12-37

43. Janevic, T., Sarah, P. W., Leyla, I., \& Elizabeth, B. H. (2012). Individual and community level socioeconomic inequalities in contraceptive use in 10 Newly Independent States: a multilevel cross-sectional analysis. International Journal for Equity in health, 11(1), 1-13.

https://doi.org/10.1186/1475-9276-11-69.

44. Dagne, H., Andualem, Z., Dagnew, B. et al. Acute respiratory infection and its associated factors among children under-five years attending pediatrics ward at University of Gondar Comprehensive Specialized Hospital, Northwest Ethiopia: institution-based cross-sectional study. BMC Pediatr 20, 93 (2020). https://doi.org/10.1186/s12887-020-1997-2

Page $13 / 16$ 
45. Kanmiki, E. W., Awoonor-Williams, J. K., Phillips, J. F., Kachur, S. P., Achana, S. F., Akazili, J., \& Bawah, A. A. (2019). Socio-economic and demographic disparities in ownership and use of insecticide-treated bed nets for preventing malaria among rural reproductive-aged women in northern Ghana. PLoS One, 14(1), e0211365.

46. Hasan, E. (2020). Inequalities in health care utilization for common illnesses among under five children in Bangladesh. BMC pediatrics, $20(1)$, 1-11. https://doi.org/10.1186/s12887-020-02109-6.

\section{Figures}

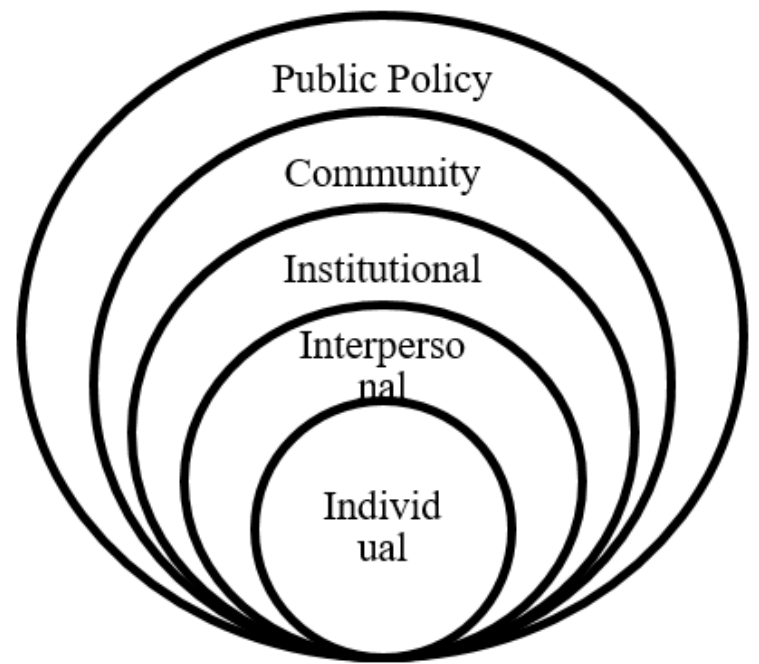

Adapted from CDC, 2002.

\section{Figure 1}

Illustrates of the social ecological model.

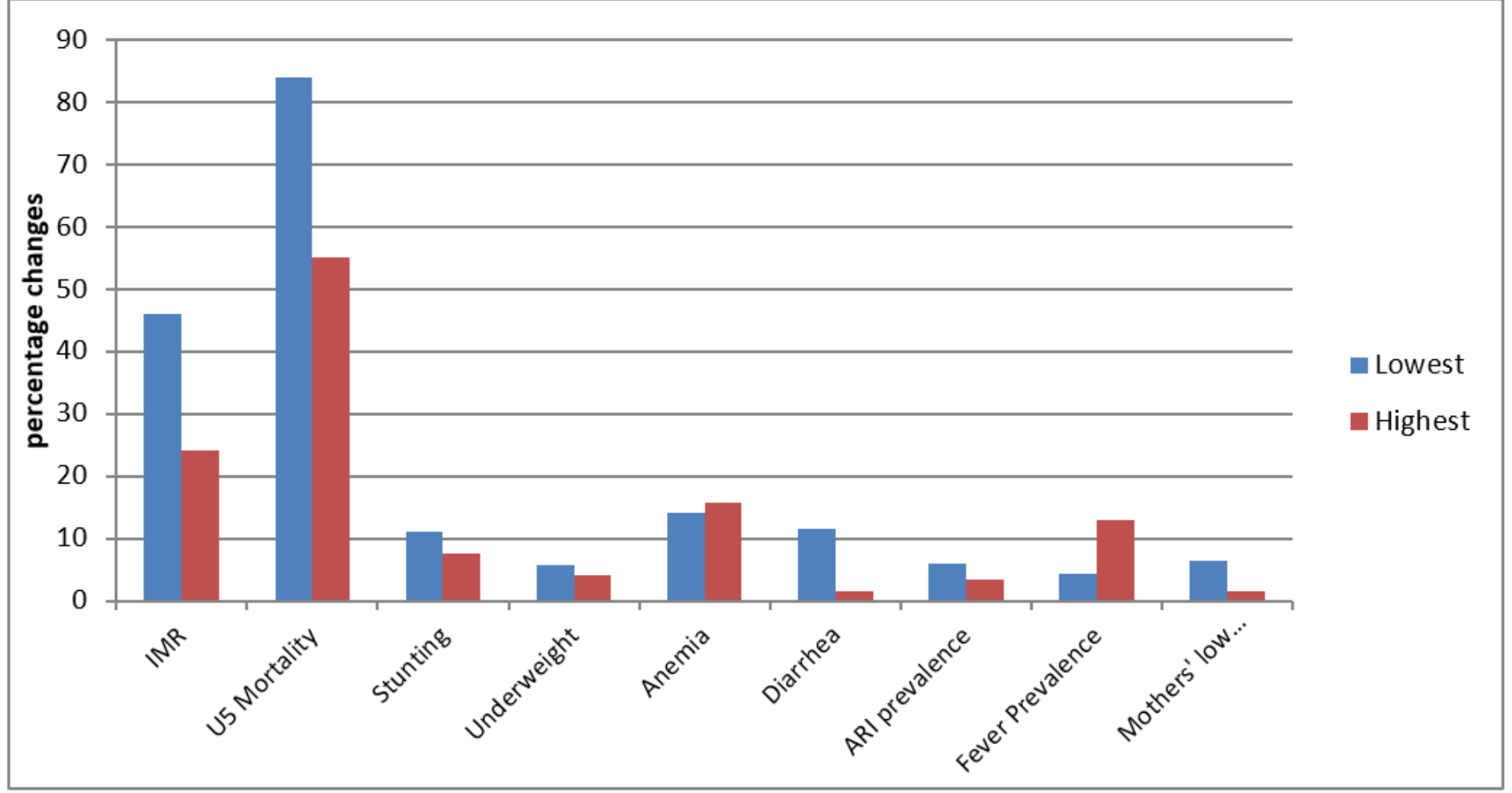

Figure 2 
shows a bar graph illustrating the absolute percentage changes in mortality and prevalence rates in outcome indicators between the lowest and highest quintiles.

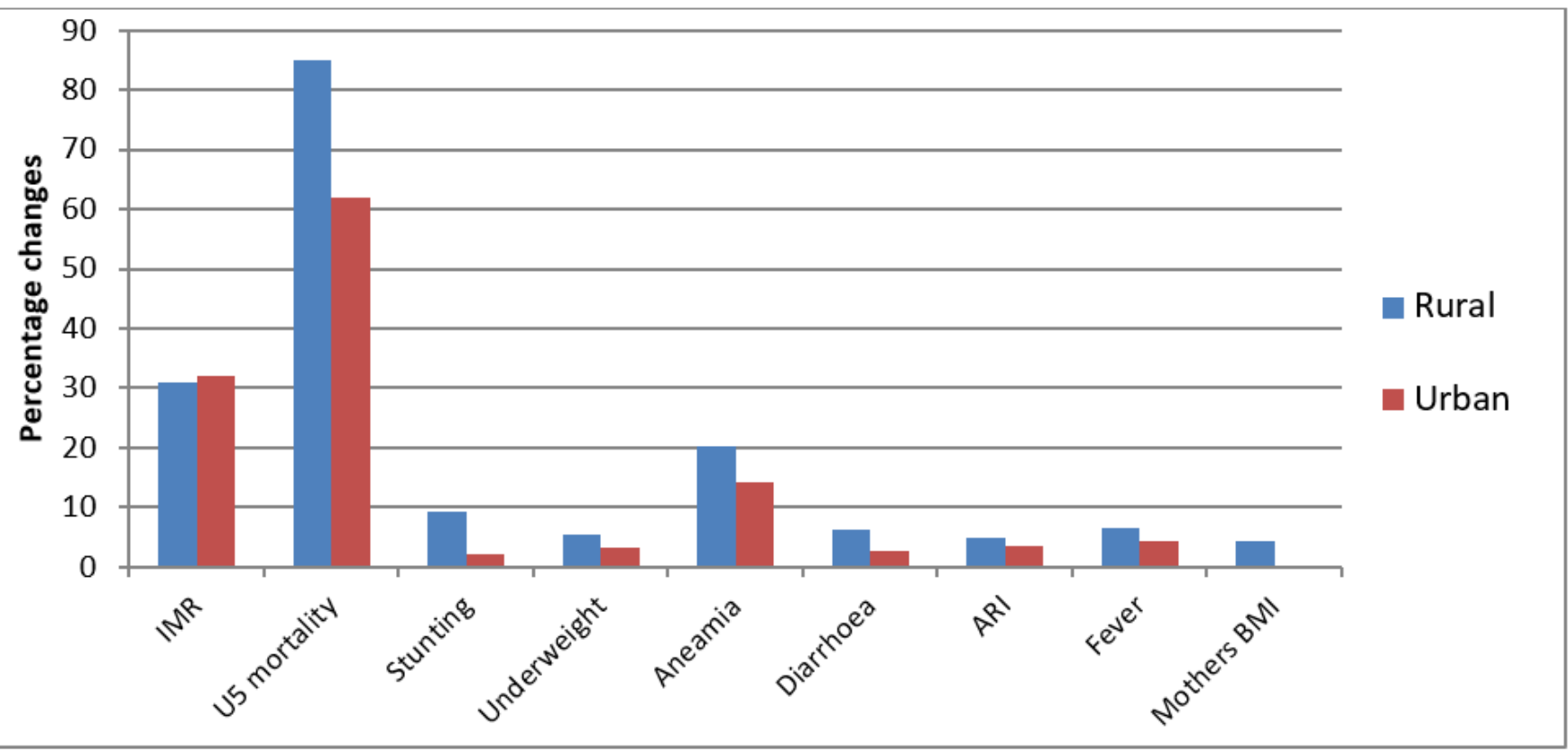

\section{Figure 3}

shows a bar graph comparing the absolute percentage changes in mortality rates and prevalence rates of outcome indicators in rural and urban areas.

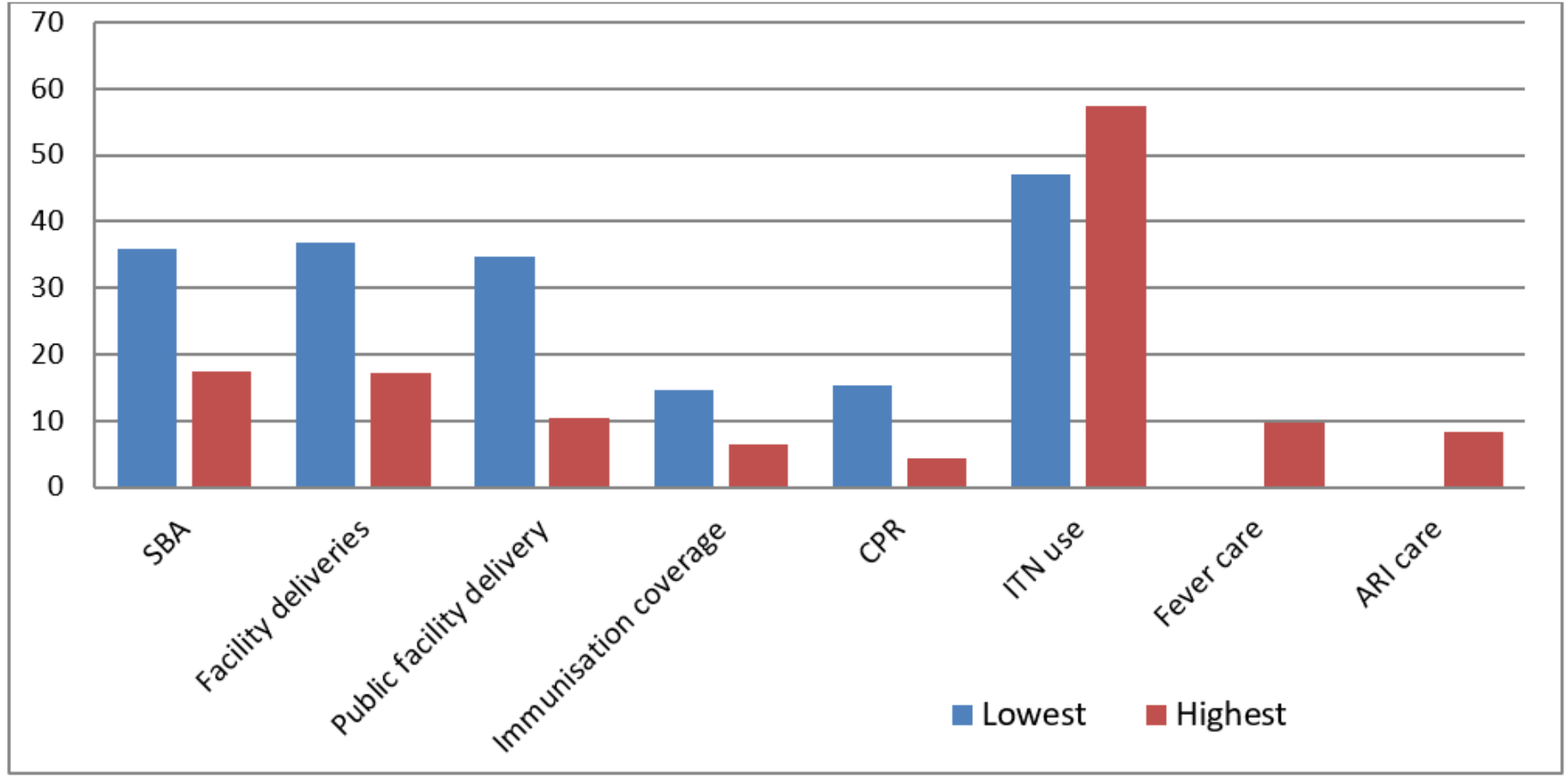

Figure 4

A bar graph depicting absolute percentage point increases in health-care utilization between the richest and poorest quintiles. 


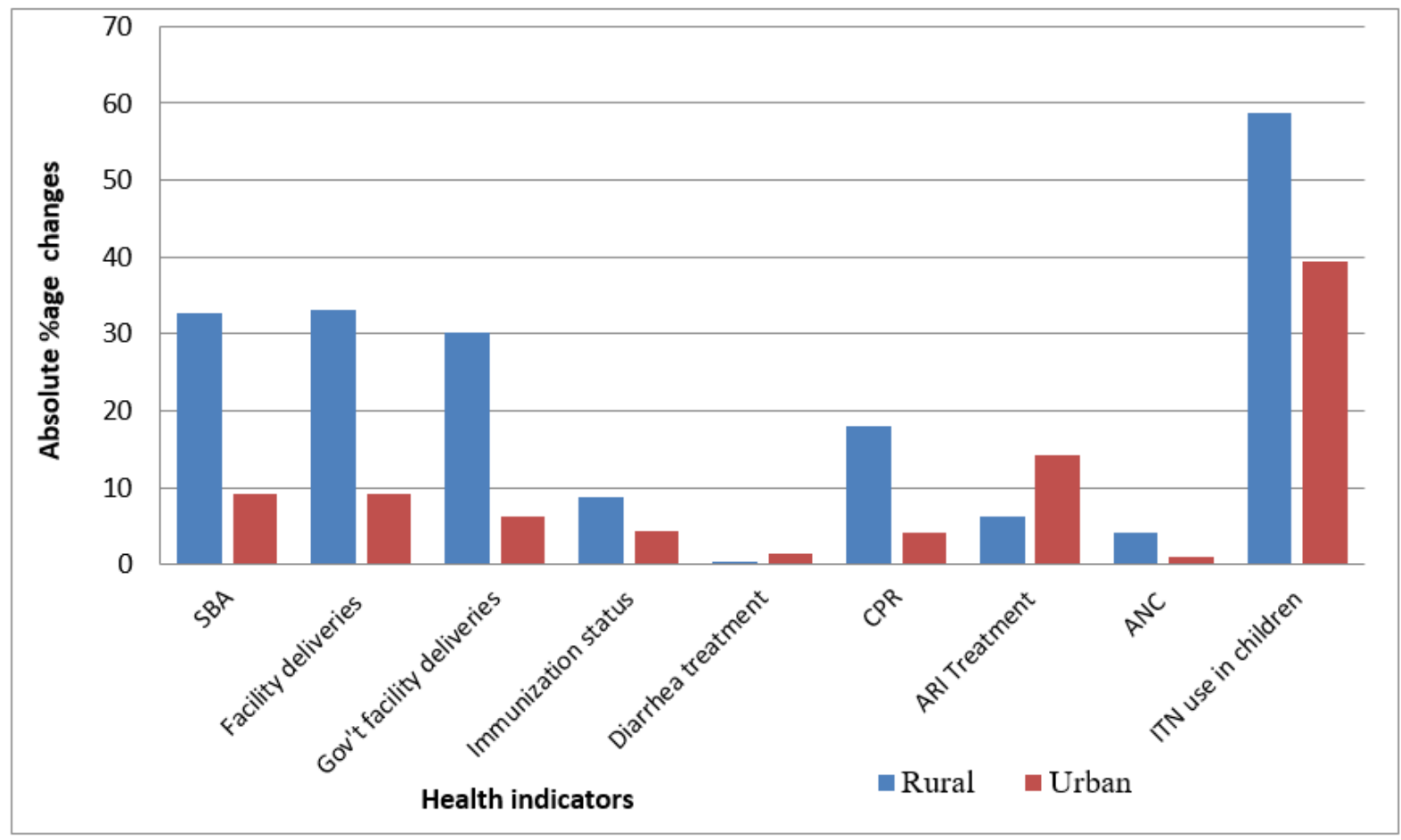

Figure 5

A bar graph depicting the absolute percentage point differences in health-care utilization between rural and urban populations. 